\title{
TDAH E O COTIDIANO ESCOLAR: UM DESAFIO DA EDUCAÇÃO ATUAL
}

\section{ARTIGO ORIGINAL}

TIRELLO, Márcia Moreira ${ }^{1}$

TIRELLO, Márcia Moreira. TDAH e o cotidiano escolar: Um desafio da educação atual. Revista Científica Multidisciplinar Núcleo do Conhecimento. Ano 04, Ed. 08, Vol. 08, pp. 137-146. Agosto de 2019. ISSN: 2448-0959

\section{RESUMO}

O presente ensaio objetiva refletir sobre as dificuldades, muito comuns nas escolas da atualidade, de se estruturar um processo ensino-aprendizagem efetivo com crianças e/ou adolescentes que apresentam Transtorno de Déficit de Atenção e Hiperatividade - TDAH. Essa reflexão se baseia em alguns referenciais teóricos, buscando esclarecer dificuldades diárias de se trabalhar com esse público e discutir sugestões metodológicas, que podem auxiliar, tanto professores, estudantes, quanto as famílias, no processo de inclusão em sala de aula e na construção de um conhecimento efetivo dos nossos educandos. A análise do referencial teórico indica necessidade de formação de educadores para lidar com essa realidade. Não se apresenta a intenção de fazer diagnósticos, uma vez que isso necessita de formação específica, e sim discutir a eficácia da atuação educacional para os indivíduos laudados com TDAH. Por fim discute a necessidade de adequação à presença desses alunos no cotidiano escolar, que são em número cada vez maior, pois os mesmos têm capacidade de elaborar e produzir diferentes tipos de conhecimentos, necessitando

\footnotetext{
${ }^{1}$ Graduada em Letras Vernáculas pela Universidade do Estado da Bahia, Especialista em Literatura Brasileira pela Universidade do Estado da Bahia e Mestranda em Ciências da Educação pela The Grendal College And University - Unigrendal.
} 
para tanto de ambientes e estímulos que favoreçam sua inclusão e desenvolvimento cognitivo.

Palavras-chave: Transtorno de Déficit de Atenção e Hiperatividade, inclusão social, cotidiano escolar inclusivo.

\section{INTRODUÇÃO}

A escola sempre foi entendida como um espaço de desenvolvimento, de aprendizagem de conteúdos diversos e de formação de cidadãos capazes de se inserir no contexto social de forma adequada e competente. Porém, o desenvolvimento dessa sociedade, principalmente nos últimos 20 anos, tem revelado que essa função destinada à escola tornou-se um processo extremamente complexo devido às transformações por que passaram as famílias e consequentemente a sociedade como um todo. O modelo educacional que considerava correto professor ensinar porque é detentor do conhecimento e aluno aprender porque é sua obrigação já não cabe na formatação de sociedade que vivemos hoje.

Hargreaves (2004), afirma que os professores de hoje, precisam estar comprometidos e permanentemente engajados na busca, no aprimoramento, no autoacompanhamento e na análise de sua própria aprendizagem profissional, uma vez que mais educação escolar nem sempre corresponde a uma aprendizagem melhor. Segundo Demo (2004), é função do professor, consequentemente da escola, ajudar a estruturar a fundamentação e argumentação do que o aluno tem a dizer.

A evasão escolar, que vem se apresentando como uma triste realidade, é uma das consequências dessa dificuldade que a escola apresenta em lidar com a diversidade atual e muitos de nós, educadores, nos perguntamos por que tantos alunos desistem de estudar. Dados do INEP - Instituto Nacional de Estudos e Pesquisas Educacionais - mostram que 12,9\% e 12,7\% dos alunos matriculados na $1^{\circ}$ e $2^{\circ}$ séries do Ensino Médio, respectivamente, evadiram da escola entre os anos de 2014 e 2015 (BRASIL, 2017). Inicialmente é necessário esclarecer que existem diversas causas que levam crianças e adolescentes a abandonarem os estudos e só esse tema mereceria uma 
reflexão própria e detalhada, mas podemos citar a dificuldade que os alunos têm em se concentrar nos conteúdos trabalhados, e por isso a não compreensão dos mesmos, como um dos motivos mais significativos que levam a essa evasão.

Agitação, falta de concentração, comportamento inquieto, são alguns indicadores de que os alunos não estão gerindo sua aprendizagem como deveriam e muito provavelmente se sentem incapazes porque não conseguem atribuir sentido ao que está sendo trabalhado. O Transtorno de Déficit de Atenção e Hiperatividade pode ser a causa desse comportamento inadequado ao ambiente escolar que, muitas vezes por falta de conhecimento, é considerado como indisciplina ou deficiência de capacidade cognitiva. E nós, educadores, precisamos ter como objetivo maior desenvolver as potencialidades dos nossos alunos, reavaliando os processos pedagógicos que construímos diariamente para tentar diminuir esse quadro de evasão escolar.

Durante muitos anos, e ainda em nossos dias, há uma tendência a atribuir o fracasso escolar do aluno, exclusivamente a ele. Desse modo, a escola fica isenta da responsabilidade pela sua aprendizagem, ou não aprendizagem, cabendo a profissionais diversos a identificação dos problemas inerentes a serem encaminhados e solucionados fora da escola.

O fracasso da criança passa a ser explicado sob diversas denominações e causas, como distúrbios, disfunções, problemas, dificuldades, carências, desnutrição, família desestruturada, dentre outras, situadas mais próximo das patologias e de causalidade social do que de situações escolares contextuais (BRASIL, 1998, p. 27).

Fato é que qualquer que seja a causa ou as causas do fracasso escolar, ela(s) precisa ser investigada, tanto pela equipe pedagógica quanto pela família, com a ajuda de profissionais adequados, pois buscar informações é a mais eficiente forma de entender e ajudar esses alunos a desenvolver suas potencialidades, sejam eles portadores ou não de alguma síndrome. O segundo artigo da Lei das Diretrizes e 
Bases da Educação de 1996 diz que a cidadania deve ser construída através da educação familiar e formal (BRASIL,1996).

Muitos são os desafios de se fazer educação de qualidade no mundo atual e dentre elas encontra-se a inclusão nas escolas regulares dos estudantes portadores do TDAH. Fomentar o desenvolvimento cognitivo, a construção do conhecimento, e a inserção do indivíduo laudado como TDAH no seu contexto social, apresenta-se como o cerne dessa busca pela inclusão efetiva dos mesmos, não só no processo educacional mas principalmente na formação holística do indivíduo. Precisamos entender esses pontos para cumprir nossa função como professores mediadores dessa construção da ética e cidadania.

\section{DESENVOLVIMENTO}

Historicamente, podemos observar que o ambiente escolar é excludente com os indivíduos que não conseguem corresponder ao modelo de aprendizagem considerado satisfatório pela sociedade, principalmente aqueles que são portadores de algum tipo de necessidade especial. Apesar de ser hoje um consenso no meio acadêmico que esses devem e têm o direito de frequentar escolas denominadas regulares, muito pouco tem sido feito para capacitar equipes pedagógicas e famílias para auxiliarem nessa inclusão.

As políticas educacionais existentes na maioria das escolas brasileiras infelizmente ainda engatinham no que se refere ao domínio conceitual do que seja inclusão escolar. Receber um aluno portador de necessidade especial é uma grande responsabilidade, pois se faz necessária a adequação de planejamentos e atividades que realmente funcionem como integradoras desses indivíduos, e isso exige, entre outras ações, qualificação de professores, adequação de espaços físicos e principalmente fomentação de metodologias de ensino que valorizem formas diferenciadas de conhecimentos e valorização de habilidades diversas. Segundo os PCN's:

Art. 2‥ A educação, dever da família e do Estado, inspirada nos princípios de liberdade e os ideais de solidariedade humana, tem por 
finalidade o pleno desenvolvimento do educando, seu preparo para o exercício da cidadania e sua qualificação para o trabalho (BRASIL, 1996, p.1).

Segundo Glat e Blanco (2007), a educação inclusiva é um processo progressivo e contínuo de absorção do aluno com necessidades educacionais especiais pela escola regular. Este pressupõe, simultaneamente, a adaptação da instituição e da cultura escolar para atuar com o aluno e a adaptação deste aluno para que possa usufruir plenamente do processo educacional. Nosso foco aqui se deterá na inclusão dos alunos diagnosticados com TDAH.

Desde meados do Século XIX, já existiam na Alemanha alguns estudos sobre esse transtorno. Mas infelizmente o que se tem confirmado, através de pesquisa científica e estudos de seriedade comprovada, ainda não é suficiente para entendermos com total clareza quais são de fato as melhores estratégias para ajudar os indivíduos portadores desse distúrbio.

Sabe-se, portanto, que o TDAH compromete de modo marcante a vida da criança e dos adultos que a cercam, pois é uma condição que promove dificuldades, como controle de impulsos, concentração, memória, organização, planejamento e autonomia. E envolve uma grande pluralidade de dimensões implicadas, tais como comportamentais, intelectuais, sociais e emocionais (BENCZIK, 2010, p. 26).

Fazer um diagnóstico de TDAH é uma tarefa complexa, pois deve ser feito por um profissional capacitado, através da observação do comportamento geral da criança e/ou adolescente em vários ambientes, tais como escola, casa, e outros ambientes coletivos e individuais frequentados pelo mesmo, pois não existe um exame clínico ou laboratorial que apresente esse diagnóstico. O Manual Diagnóstico e Estatístico de Transtornos Mentais com edição em 2014, descreve alguns sintomas do TDAH e diz que a pessoa precisa apresentar pelo menos seis desses sintomas em mais de um ambiente em que frequenta por pelo menos seis meses. São vários os possíveis 
sintomas, mas podemos citar como exemplo desatenção, dificuldade em seguir instruções ou terminar tarefas, falta de organização temporal e/ou espacial, distração com facilidade, demonstra não ouvir comandos ou perguntas, agitação corporal e mental, dificuldade em esperar sua vez de falar, levantar-se com frequência, falta de interesse em atividades longas ou silenciosas, entre outros.

Para se elaborar um diagnóstico correto desta condição, são necessárias várias avaliações, muitas vezes com abordagem multidisciplinar. A avaliação clínica com médico deve coletar informações não apenas da observação da criança durante a consulta, mas também realizar entrevista com os pais e/ou cuidadores dessa criança, solicitar informações da escola que a criança frequenta sobre seu comportamento, sociabilidade e aprendizado, além da utilização de escalas de avaliação da presença e gravidade dos sintomas (REIS ET AL, 2011, p. 11).

Como alguns desses sintomas são comuns a determinadas faixas etárias, é necessário que haja uma avaliação séria e criteriosa, para que o diagnóstico corresponda à condição real da criança e/ou adolescente. Em alguns casos, de acordo com o grau em que se apresenta, o médico responsável pelo acompanhamento opta pela utilização de medicamentos que auxiliam na diminuição dos sintomas, embora seja de absoluta necessidade o desenvolvimento de metodologia adequada e contínua para a realização de tarefas tanto cotidianas quanto escolares.

No ambiente escolar, faz-se necessário que o educador esteja atento à rotina do aluno, observe como ele se relaciona com os colegas, como administra o tempo na realização de atividades, e principalmente quando e como se dá a dispersão e falta de atenção. Infelizmente, nossa realidade escolar brasileira não facilita o trabalho de mediação do professor, pois geralmente as salas são cheias e dar atenção individual a cada aluno é uma tarefa complexa. Mas apesar dessa complexidade, a sala de aula ainda é um espaço muito importante para que as crianças e/ou adolescentes diagnosticados com TDAH avancem na superação de suas dificuldades. 
Por envolver alterações comportamentais, como dificuldade em permanecer sentado, ansiedade, falta de concentração em tarefas prolongadas, desorganização com materiais pessoais e coletivos ou ausência de habilidade em administrar regras durante as brincadeiras, esses alunos podem apresentar autoestima reduzida, fato esse que interfere em sua relação com o mundo exterior. Na escola, esse comportamento muitas vezes é definido como indisciplina e isso tem um impacto muito negativo nas relações interpessoais.

Dialogar com a família apresenta-se como prática indispensável nessa trajetória de inserção de alunos com necessidades especiais. No caso dos TDAH, esse diálogo precisa ser mais intenso e contínuo, porque a mediação, tanto no espaço escolar quanto familiar, é muito importante para vencer as dificuldades específicas desse público. É muito comum criar-se um rótulo de desinteresse nesses casos, e através da troca de informações e procedimentos adequados, é possível promover um avanço real na construção da autonomia e interação social.

Nesse contexto, é importante que professores e coordenadores sejam aliados no processo de inclusão dos alunos com TDAH, não só buscando estratégias que favoreçam a interação social mas também utilizando práticas pedagógicas que fomentem a construção do conhecimento. O método avaliativo pode ser reelaborado, de acordo com a natureza dos conteúdos, sendo composto por atividades diversificadas e não apenas provas. Exercícios repetitivos e longos apresentam-se ineficazes, e podem ser substituídos por interações orais ou registros escritos mediados pelo professor. Oferecer um tempo diferenciado e ambiente tranquilo (sem muitos estímulos visuais e auditivos externos) durante as avaliações escritas, pode também favorecer um melhor desempenho.

Sempre que for possível, esses alunos devem receber uma atenção individualizada, podem ser colocados para sentar-se ao lado de outros alunos com bom desempenho escolar e que possam ajudá-los na resolução de atividades; utilizar a tecnologia, como por exemplo o laboratório de informática também é uma boa estratégia para manter a atenção desse público, propondo tarefas, jogos ou desafios a serem realizados no computador. Outra sugestão interessante é criar o hábito de anotar comandos 
apresentados nas atividades, uma vez que a dificuldade de concentração faz com que a interpretação, e por consequência o entendimento do que deve ser feito, se torne um problema.

Desenvolver o hábito de anotar o passo a passo das atribuições que o aluno deve realizar pode facilitar a resolução de questões, pois é uma ferramenta que o aluno pode recorrer quando se perder durante a realização de tarefas. O contato visual constante também é importante para manter o foco de atenção na explicação do conteúdo, além de evitar proximidade com corredores, portas e janelas, que são canais de comunicação com o ambiente exterior (WEISS; CRUZ, 2007).

\section{CONCLUSÃO}

Diante desse desafio de incluir nas escolas regulares todos os alunos, portadores ou não de necessidades especiais, faz-se necessário que a escola aprenda a conviver com os comportamentos diversos que constituem as salas de aula da atualidade. Possibilitar ao aluno diagnosticado com TDAH o acesso e principalmente a permanência do mesmo no ambiente escolar deve ser a meta básica das famílias e educadores. E para alcançar essa meta é necessário conhecer os sintomas, observar as dificuldades e buscar ferramentas que auxiliem cada indivíduo a construir seu conhecimento.

A escola deve incentivar a socialização dos alunos diagnosticados com TDAH, trabalhando na coletividade o respeito e a cooperação mútua, uma vez que a educação inclusiva é mais do que um direito, é o caminho para a aceitação da diversidade social e comportamental que a atualidade apresenta. Construir propostas pedagógicas com paradigmas e concepções inclusivos é uma necessidade do contexto social da atualidade e deve envolver toda a comunidade escolar, ressignificando assim a valorização das potencialidades diversas.

É, portanto, papel da escola possibilitar o mesmo processo de ensino para os alunos especiais, pois, é no ambiente educacional que a criança vai se socializar. A educação 
inclusiva remete a ideia de que a escola regular é de todos e confirma o que está escrito na lei, que somos todos iguais (FERREIRA; FERREIRA, 2007).

Especialmente nos casos de TDAH, o processo de ensino-aprendizagem deve ser acompanhado tanto pela família quanto pela escola, pois provoca uma condição de desatenção que extrapola os limites das relações familiares ou escolares, envolvendo praticamente todas as áreas comportamentais do indivíduo. Por isso, buscar alternativas que facilitem a rotina de estudos é compromisso dessas duas instituições.

Construir espaços de convivência que respeitem indivíduos, independente de síndromes ou transtornos, precisa ser objetivo da educação como um todo e para atingir essa meta o projeto político pedagógico das escolas devem propor estratégias para a formação integral do indivíduo. Isso implica em uma busca constante por metodologias integradoras, através da formação continuada de todos os profissionais envolvidos na educação.

Partindo do pressuposto que o método avaliativo é uma forma de classificar o conhecimento, os alunos com TDAH necessitam de uma abordagem diferenciada nessa questão, através de uma prática pedagógica inclusiva que utilize ferramentas múltiplas para vencer alguns obstáculos específicos e comuns a esses indivíduos. Insistir em métodos avaliativos muito tradicionais, que se resumem a provas escritas ou atividades de repetição apenas, é contribuir para a não adequação dos alunos com dificuldade de atenção.

Tão importante quanto a capacitação dos profissionais da área de educação é a conscientização das famílias que a criança/adolescente com TDAH precisa de acompanhamento contínuo dos pais e responsáveis, que não podem esperar que a escola sozinha promova a aceitação e inclusão efetiva desses indivíduos. Faz-se necessária então a parceria família/escola, com o objetivo de transformar o espaço escolar em um ambiente acolhedor para todos os alunos, contribuindo assim para a solidificação da ética e da cidadania. 
Reconhecer e valorizar a diversidade são condições humanas que beneficiam a aprendizagem - a limitação do individuo deve ser considerada apenas mais uma informação sobre o mesmo, não a descartando na criação de planos de ensino, porém, fazendo uso de uma construção alternativa de possibilidades promissoras à autonomia escolar e social do sujeito, disseminando assim, o valor de direitos iguais. (MANTOAM; PIETRO, 2006)

\section{REFERÊNCIAS}

BENCZIK, Edyleine B. P. Transtorno de Déficit de Atenção/Hiperatividade: atualização diagnóstica e terapêutica. São Paulo: Casa do Psicólogo, 2010.

BRASIL. Lei Federal no 9394/96. Lei de Diretrizes e Bases da Educação Nacional. Brasília, 1996.

BRASIL. Ministério da Educação. Instituto Nacional de Estudos e Pesquisas Educacionais. INEP. 2017. Disponível em: <http://www.edudatabrasil.inep.gov.br>. Acesso em: 05 de jun. de 2019.

BRASIL. Ministério da Educação. Parâmetros Curriculares Nacionais Adaptações curriculares: estratégias para a educação de alunos com necessidades educacionais especiais. Brasília, 1998.

DEMO, P. Ser professor é cuidar que o aluno aprenda. Porto Alegre: Artmed, 2004.

FERREIRA, Maria Cecília C.; FERREIRA, Júlio Romero. Sobre inclusão, políticas públicas e práticas pedagógicas. In: GÓES, Maria Cecília R.; LAPLANE, Adriana Lia F. (Org.). Política e Práticas de Educação Inclusiva. São Paulo: Autores Associados, 2007. 1. ed. Cap. 2, p. 21-48.

GLAT, Rosana; BLANCO, Leila Macedo V. Educação Especial no contexto de uma Educação Inclusiva. In: GLAT, Rosana (Org.). Educação Inclusiva: cultura e cotidiano escolar. Rio de Janeiro: 7 Letras, 2007, Cap.1, p. 19-39. 
HARGREAVES, A. O ensino na sociedade do conhecimento: educação na era da insegurança. Porto Alegre: Artmed, 2004.

MANTOAM, Maria Teresa E.; PRIETO, Rosângela Gavioli. Inclusão escolar. São Paulo: Summus, 2006.

Manual Diagnóstico e Estatístico de Transtornos Mentais: DSM-5; tradução: Maria Inês Correa Nascimento et al., 5ª edição. Porto Alegre: Artmed, 2014.

REIS, Aline et al. TDAH - Transtorno do déficit de atenção e hiperatividade: uma conversa com educadores. São Paulo: Novartis, 2011.

WEISS, Alba Maria L.; CRUZ, Mara Monteiro. Compreendendo os alunos com dificuldades e distúrbios de aprendizagem. In: GLAT, Rosana (Org.). Educação Inclusiva: cultura e cotidiano escolar. Rio de Janeiro: 7 Letras, 2007. Cap.4, p. 69-82.

Enviado: Julho, 2019.

Aprovado: Setembro, 2019. 